\title{
GOVERNANÇA LOCAL PARA MANEJO FLORESTAL NA AMAZÔNIA
}

\section{Gabriel Medina}

\section{Introdução}

O manejo efetivo de florestas da Amazônia por comunidades tradicionais e indígenas pode contribuir para o desenvolvimento rural sustentável. Contudo, o marco legal e institucional para o uso dos recursos florestais pelas comunidades, caracterizado pela imposição de pacotes técnico-gerenciais definidos por especialistas, torna virtualmente impossível o engajamento de comunidades em atividades legalmente reconhecidas sem suporte externo considerável para superar barreiras técnicas, legais e financeiras (Medina et al., 2009a). Em decorrência do sucesso limitado de iniciativas promovidas pelas políticas públicas para a Amazônia, torna-se necessário explorar cuidadosamente as possibilidades de promoção de sistemas de governança desenvolvidos pela própria comunidade como alternativa para o

Artigo recebido em 29/04/2010

Aprovado em 30/06/2011 uso de recursos florestais de acordo com os interesses e as capacidades locais (Medina et al., 2009b).

Para tanto é fundamental conhecer as circunstâncias que podem favorecer comunidades rurais a desenvolver sistemas de governança local na fronteira amazônica. $\mathrm{O}$ processo para o estabelecimento de sistemas de gestão florestal por comunidades é particularmente complexo em áreas de fronteira, onde a população local tem que dividir espaço com atores externos imigrantes em contextos institucionais novos e dinâmicos (Martins, 1997).

A literatura sugere que comunidades na fronteira amazônica podem enfrentar três desafios para o estabelecimento de sistemas efetivos de gestão local. Primeiro, precisam desenvolver normas para regular o acesso e o uso de seus recursos. Pesquisas prévias ilustraram casos em que a própria comunidade definiu regras para a coleta sustentável de recursos de uso comum (Arnold, 1998; Ostrom, 1999; Conroy et al., 2002; Lurie e Hibbard, 2008; 
Sick, 2008; Flint et al., 2008). Entretanto, outros estudos indicam restriçôes significativas enfren-tadas pelas comunidades para estabelecer esses sistemas de governança, incluindo suas próprias restrições físicas e materiais (Cleaver, 2005) e desigualdades internas de poder (Campbell et al., 2001; Pérez-Cirera e Lovett, 2006).

Segundo, as comunidades precisam se organizar para implementar seus sistemas de governança e se expressar politicamente. Estudos prévios sugerem que comunidades enfrentam vários desafios para identificar interesses em comum que poderiam servir de base para a sua organização (ver, por exemplo, Futemma et al., 2002; Ballabh et al., 2002; Thorp et al., 2005; Abers, 2007). Na fronteira amazônica, em particular, as relações paternalistas com atores externos podem gerar dependência e falta de organização local (Medina e Shanley, 2004). De acordo com Scott (1985), grupos socialmente subordinados ao longo da história raramente se dão ao luxo da atividade política organizada e aberta e, normalmente, utilizam-se de resistência individualizada e passiva.

Terceiro, as comunidades precisam interagir efetivamente com instituições externas, em especial com agências de governo, para que seus sistemas sejam reconhecidos pela sociedade de forma geral. Pesquisas anteriores mostraram que, onde a ação coletiva tem emergido, as organizações representativas da comunidade encaram dificuldades políticas para ter suas demandas levadas em consideração em virtude da natureza e da fragilidade das instituições locais (Albaladejo e Veiga, 2002; Dove, 1993; Muñoz et al., 2007; Brockington, 2007). De acordo com Muñoz et al., a interação exitosa com a sociedade depende de parceiros e estruturas eficientes de comunicação. No entanto, estes geralmente não são acessíveis às comunidades locais dos países da América do Sul (Martins, 1999; Muñoz et al., 2007).

Entretanto, estudos sobre movimentos sociais mostraram que, em circunstâncias particulares, comunidades da fronteira amazônica foram capazes de se organizar e implementar seus próprios sistemas de regulação do acesso e uso dos recursos naturais. A força histórica dos movimentos políticos rurais nos países da América Latina foi demonstrada pela luta das comunidades rurais pelo acesso à terra (Martins, 1981; Ianni, 1985). Muitos estudos na regiāo amazônica confirmaram a emergência de movimentos sociais que lutaram pelo acesso a recursos naturais com êxito (Leroy, 1991; Pinedo-Vazquez et al., 1992; Richards, 1997; Futemma et al., 2002; Garcia-Linera, 2004; Bonifaz, 2005).

Este estudo explora as circunstâncias sob as quais as comunidades na fronteira amazônica podem desenvolver sistemas de governança local para a gestão de seus recursos naturais. Detém-se particularmente nas circunstâncias sob as quais as comunidades podem:

(1) Desenvolver sistemas de gestão de acordo com seus interesses e capacidades.

(2) Identificar interesses comuns e se organizar para implementar seus sistemas.

(3) Ter seus sistemas reconhecidos pela sociedade nacional e internacional.

\section{Áreas de estudos e métodos}

Esse estudo foi realizado entre os anos de 2005 e 2008 em quatros áreas onde as comunidades desenvolveram sistemas de governança comunitária para explorar recursos naturais: a província de Vaca Diez, na região de Beni, na Bolívia; os municípios de Xapuri, no estado do Acre, e Porto de Moz, no estado do Pará, ambos no Brasil; e o distrito de Masisea, na região de Ucayali, no Peru. Todas as áreas são fronteiras típicas com economias em expansão, caracterizadas pelo contato cada vez maior entre as comunidades locais e imigrantes, tais como madeireiros e fazendeiros criadores de gado (Martins, 1997; Salgado e Kaimowitz, 2003; De Jong, 2004).

A primeira fase do estudo consistiu em uma imersão nas áreas de trabalho para identificar os aspectos mais relevantes que influenciam as comunidades no uso de seus recursos naturais. Esta fase foi seguida por uma revisão sistemática da literatura sobre os aspectos identificados em campo, o que culminou na elaboração de várias perguntas de pesquisa, além de uma lista de aspectos que deveriam ser observados em campo. Depois, uma segunda fase de coleta de dados no campo por meio de entrevistas sobre a história dos movimentos sociais em cada área de estudo, além da observação das 
práticas de gestão implantadas. A análise foi basea da no diálogo estabelecido entre os autores e os interlocutores entrevistados. Durante as entrevistas, representantes de movimentos sociais, assim como famílias das comunidades, foram convidados a analisar suas histórias além de comentar sobre interpretações fornecidas pelos pesquisadores. Esta informação foi então transcrita e agrupada de acordo com os diferentes aspectos avaliados na pesquisa.

Líderes e outros representantes das organizações relevantes da comunidade também foram entrevistados. Na Bolívia, as entrevistas foram conduzidas principalmente por representantes da Federação de Camponeses da Província de Vaca Diez, que representa 56 comunidades afiliadas, compostas de pequenos agricultores nos municípios de Riberalta e Guayaramerin. No Acre, a presidente do Sindicato dos Trabalhadores Rurais de Xapuri, que representa 2.758 famílias de seringueiros de diferentes comunidades, foi entrevistada. No Pará, o estudo teve como alvo o Comitê de Desenvolvimento Sustentável de Porto de Moz, que congrega várias organizações de base com destaque para vinte associações de comunidades rurais. Por fim, no Peru, o representante da organização indígena Ordim foi entrevistado; essa organização reúne vinte comunidades indígenas na província de Masisea. As entrevistas foram baseadas na origem dos seus movimentos, no processo de organização e em suas conquistas.

Além disso, em cada área, duas comunidades foram selecionadas para estudos de caso, com quatro a seis famílias entrevistadas em cada comunidade sobre os motivos pelos quais elas participaram ou não dos movimentos sociais estudados, assim como sobre suas demandas, seus papéis no movimento e suas conquistas pessoais. Cada comunidade recebeu três ou quatro visitas durante o período de dois anos, e cada visita durou de três a seis dias. As comunidades estudadas não foram identificadas nesse artigo, para preservar os entrevistados.

O método analítico foi usado para interpretar as circunstâncias que causaram a emergência de sistemas de gestão florestal pelas comunidades. Inicialmente, a pesquisa caracterizou as formas de acesso e uso de recursos naturais pelas comunidades antes do estabelecimento dos sistemas de governança. Em seguida, foi feita a identificação das circuns- tâncias que levam comunidades sem organização formal prévia a investir energia para criar organizações que representassem seus interesses. Por fim, a pesquisa abordou as circunstâncias pelas quais as comunidades tiveram seus sistemas reconhecidos, comparando os casos exitosos com aqueles que não tiveram sucesso.

\section{Resultados}

Nas quatro áreas de estudo atualmente existem sistemas de governança local para regular o acesso aos recursos locais. Em Vaca Diez (Bolívia), as comunidades desenvolveram sistemas para controlar o acesso a áreas de coleta de castanha-do-brasil, fonte importante de recursos financeiros. As comunidades dividiram sua área em parcelas individuais de cerca de 500 ha, cada parcela manejada por uma família. As famílias proibiram o acesso de atores comerciais externos a essas áreas e também a conversão das florestas para outros usos. Para implementar seus sistemas, as comunidades mobilizaram-se em torno da Federação de Camponeses de Vaca Diez e iniciaram protestos públicos conhecidos como marchas em que agricultores caminharam por muitos dias até a sede do governo boliviano (Bonifaz, 2005). As famílias demandaram proteção para suas áreas de floresta e apoio à manutenção de sua economia extrativista baseada na coleta de castanha. Como resultado, a lei de reforma agrária foi alterada para dar a cada família o direito a até 500 ha de terra. Em 2007, vinte comunidades na área de estudo receberam o título de sua área. Adicionalmente, grandes proprietários precisam agora provar para o governo que suas áreas são produtivas e cumprem a função social e econômica, sob pena de ter suas terras destinadas para fins de reforma agrária.

Em Xapuri (Acre, Brasil), as famílias definiram normas para regular o acesso a áreas de extração de borracha e coleta de castanha-do-brasil. Essas áreas de floresta (seringais) foram tradicionalmente divididas em parcelas individuais de 400 a 600 ha (colocaçôes) que são manejadas por cada família. As famílias definiram que essas colocações não poderiam ser vendidas ou exploradas por fazendeiros de fora. Para implementar seu sistema, elas se organizaram 
em torno do Sindicado dos Trabalhadores Rurais de Xapuri e iniciaram manifestaçōes conhecidas como empates - os seringueiros paravam em frente dos empregados das fazendas e, de forma pacífica, evitavam o corte das árvores e a abertura de novas áreas para pastagem. As famílias reclamavam o direito de permanecer em suas colocações e de manter sua economia extrativa baseada na borracha e na coleta de castanha. Como resultado, as demandas foram reformuladas e reconhecidas dentro de um novo marco legal que incluiu a criação de reservas extrativistas a partir de 1990 e de projetos de assentamentos agroextrativistas a partir de 1989, os dois inspirados no sistema tradicional de colocações (Allegretti, 1990).

Em Porto de Moz (Pará), as famílias estabeleceram acordos de pesca em rios locais, fiscalizando o acesso de geleiras e áreas comunitárias de florestas para controlar a extração predatória por grandes madeireiras. Mais de dez comunidades firmaram acordos de pesca incluindo regras sobre quem tem permissão para pescar, quais equipamentos podem ser usados, períodos de pesca e quantidade de pescado que pode ser vendida por família local (Moreira, 2004). Nove comunidades demarcaram áreas comunitárias para regular o uso de produtos florestais e caça. Essas áreas (de cerca de 10 mil ha cada) estão normalmente localizadas no fundo dos lotes individuais das famílias que ficam nas margens dos rios (cada lote com cerca de $100 \mathrm{ha}$ ). Os recursos florestais das áreas comunitárias não podem ser negociados com atores externos e servem como uma reserva para a expansão futura da comunidade e para atividades de manejo florestal comunitário. As famílias organizaram-se em torno do Sindicato de Trabalhadores Rurais para estabelecer os acordos de pesca e em torno do Comitê de Desenvolvimento Sustentável de Porto de Moz para demarcar as áreas comunitárias. Nos dois casos, os sistemas de governança foram implementados apenas localmente, sem reconhecimento formal pela agência de governo responsável. Posteriormente, as comunidades reformularam suas demandas seguindo o formato de reservas extrativistas inicialmente desenvolvidas no estado do Acre no contexto do movimento dos seringueiros. A Reserva Extrativista Verde para Sempre foi criada em 2004, compreendendo 1.288.000 ha e representando $74 \%$ da área do município de Porto de Moz.
Em Masisea (Peru), famílias indígenas vivendo ao longo dos rios definiram seus territórios tradicionais e estabeleceram normas para regular o acesso aos recursos naturais. Como consequência, madeireiros tiveram que passar a negociar com as comunidades a forma de explorar a madeira de suas áreas. As comunidades estruturaram-se em torno de organizações indígenas para negociar com o governo o reconhecimento de seus territórios. Como resultado, em 2007, cerca de 60\% dos territórios indígenas totalizando 12 milhōes de hectares foram demarcados e reconhecidos formalmente como pertencentes aos grupos indígenas. Mais recentemente algumas comunidades que tiveram pequenas áreas demarcadas reivindicaram a expansão de seus territórios. Regionalmente, o controle sobre pesca, caça e extração de madeira desenvolveu-se como resposta às pressões comerciais externas. Os sistemas de controle mostraram-se razoavelmente efetivos a despeito de não serem oficialmente reconhecidos ainda em muitos casos (Pinedo-Vazquez et al., 1992).

\section{Desenvolvimento de sistemas de governança}

Sistemas de regulação foram desenvolvidos em cada área de estudo depois que atores do setor privado de outras regiōes imigraram e passaram a explorar os recursos das comunidades locais sem negociação prévia (Tabela 1). Nesses estudos de caso, os sistemas de governança comunitária surgiram como uma tentativa das comunidades locais em restringir o acesso pelos atores externos a recursos de interesse local.

Em Vaca Diez, inicialmente as famílias coletaram castanha-do-brasil de áreas vizinhas às suas moradias sem nenhuma regulação interna, pois o recurso era abundante. Os sistemas de governança local regulando o acesso à castanha surgiram como uma resposta das comunidades a grandes proprietários de terras, grandes fazendeiros e madeireiros invadindo seus territórios tradicionais de coleta. Esses atores externos beneficiaram-se da reforma agrária de 1996, que destinou apenas 50 ha de terra por família rural. Sob esse marco legal, as comunidades extrativistas teriam perdido parte significativa de seus territórios. A partir da pressão 
externa, as comunidades começaram a regular o acesso a seus territórios.

A maior parte dos atores externos imigrou de outras regiōes e não tinha relação com as famílias locais. Nos casos que levaram à reação, eles invadiram as áreas das comunidades sem negociação prévia. Em uma das comunidades estudadas, diferentes atores invadiram ao mesmo tempo, alguns interessados nos estoques de castanha, outros, em madeira e outros buscando área para a criação de gado. As famílias perceberam que corriam perigo de perder sua terra e que a resistência pacífica poderia não ser suficiente, uma vez que já havia casos de assassinato de membros das comunidades. As relações conflituosas com atores externos promoveram a mobilização das comunidades para a implementação de seu sistema de governança.

Em Xapuri, onde barôes da borracha abandonaram seus seringais depois do colapso da exportaçôes em 1945, as famílias locais ficaram livres para manejar suas colocaçôes individuais. Contudo, em 1980, o governo passou a subsidiar investidores de outras regiōes do Brasil para transformar antigos seringais em grandes fazendas de gado para a exportação de carne. Como consequência, o estado do Acre experimentou a expansão maciça dos fazendeiros à custa da expulsão das famílias de seringueiros. Os investidores de outras regiōes do Brasil contratavam grupos locais para expulsar os seringueiros de suas colocaçôes legitimados pelas políticas de governo e sem se sentir obrigados a qualquer negociação com os seringueiros. Os invasores tentaram tomar posse de seringais inteiros ao plantar pastagem e construir currais para a criação de gado. Quando as famílias que estavam vivendo nas colocações mais remotas dos seringais perceberam a ameaça, começaram a se mobilizar contra os fazendeiros para manter suas colocações e defender seus direitos consuetudinários.

Em Porto de Moz, antes dos anos de 1980, as famílias rurais viviam em áreas individuais ao longo dos rios, fazendo agricultura em pequena escala, pesca e extração esporádica de madeira para o comércio local. No decorrer dessa década, pescadores comerciais (geleiras) começaram a explorar os rios locais ameaçando os meios de vida das comunidades ribeirinhas. Na década de 1990, grandes empresas madeireiras também imigraram para a região vindas de áreas onde os estoques de madeira já estavam reduzidos como o município de Breves e começaram a explorar as florestas nos fundos das comunidades sem oferecer recompensa às famílias locais. As comunidades então estabeleceram acordos de pesca para controlar o acesso das geleiras e demarcaram as áreas comunitárias para se proteger das grandes empresas madeireiras. As geleiras e as madeireiras que imigraram para o município não tinham relação anterior estabelecida com as famílias locais. Esse fato é ilustrado pela entrevista com um representante do movimento social local:

Nos anos de 1980 recebemos em Porto de Moz um grande número de pescadores comerciais vindos da área de construção da Hidrelétrica de Tucuruí (que teve construção iniciada em 1984). A pesca foi tão intensa que a cadeia local de pesca entrou em colapso. Como as geleiras estavam fazendo sobrepesca na desembocadura dos rios, os moradores rio acima começaram a sofrer com a falta de pescado. Essa ameaça rapidamente mobilizou as famílias, e a mobilização foi facilitada por diferentes fatores: as geleiras eram de outra região e poucas pessoas daqui estavam envolvidas na atividade. Para políticos locais, tomar posição contra as geleiras não representava nenhuma perda política, pois, ao contrário dos madeireiros, os pescadores não financiavam as campanhas eleitorais. Assim, alguns políticos locais se tornaram parte do movimento contra as geleiras. No entanto, essa mobilização durou apenas até que nossos pequenos madeireiros locais começaram a negociar individualmente com as famílias os direitos de explorar madeira em suas áreas. As famílias passaram a correr para a floresta buscando madeira para negociar e muitas reduziram sua participação no movimento contra as geleiras que também já haviam reduzido suas atividades. Depois da década de 1990, as comunidades reorganizaram quando grandes madeireiras vindas de outros municípios chegaram à região sem negociar com as famílias e explorando as matas vizinhas para a extração de madeira. 
Também em Masisea, as famílias indígenas viviam ao longo das margens dos rios explorando recursos naturais abundantes de forma coletiva em territórios ancestrais. No final da década de 1980, o setor madeireiro no centro comercial da cidade de Pucallpa ampliou significativamente suas atividades, e empresas começaram a acessar os territórios indígenas para e extração de madeira. As comunidades perceberam que precisavam de reconhecimento formal para suas terras como um requerimento básico para negociar os direitos de exploração de suas florestas com as empresas madeireiras e começaram a se mobilizar nesse sentido.

\section{Organização das comunidades}

Nos casos estudados, as relações entre comunidades e atores externos foram caracteristicamente impessoais e frequentemente conflituosas. Relações impessoais garantiram distanciamento entre comunidades e atores externos em contraste com relaçôes paternalistas tão comuns na Amazônia (Medina e Shanley, 2004). Em casos em que as relações também eram conflituosas, as comunidades mobilizaram-se em torno de interesses compartilhados e organizaram-se para resistir à ameaça comum.
Em todas as regiōes estudadas, as relaçōes conflituosas com atores externos levaram famílias e comunidades a criar organizaçôes representativas para defender seus interesses de forma mais efetiva na arena política e institucional. Algumas organizações representativas surgiram diretamente dos movimentos contra a invasão dos atores externos e outras existiam previamente e foram fortalecidas. Independentemente de sua origem, todas as organizaçôes nas áreas estudadas enfocaram seu trabalho na defesa das comunidades afetadas.

Em Xapuri, o Sindicato de Trabalhadores Rurais foi criado em 1977 pelo movimento para proteger os seringais contra a expansão das fazendas de gado. No início, a organização incluía apenas comunidades próximas à cidade de Xapuri, que foram as primeiras afetadas. Como os conflitos com fazendeiros se ampliaram, um número crescente de comunidades juntou-se à organização. $\mathrm{O}$ Sindicato então começou a organizar os empates para bloquear a expansão da pecuária e reivindicar os direitos das famílias às suas áreas e recursos.

Nos anos de 1980, em Porto de Moz, o já existente Sindicato de Trabalhadores Rurais começou a apoiar as comunidades na luta contra pescadores comerciais. Os primeiros acordos de pesca foram

Tabela 1

Contexto de Emergência de Sistemas de Governança Local

\begin{tabular}{|c|c|c|c|c|}
\hline & Vaca Diez & Xapuri & Porto de Moz & Masisea \\
\hline Recurso & Castanheiras & $\begin{array}{l}\text { Seringueiras e } \\
\text { castanheiras }\end{array}$ & Peixe e madeira & Madeira \\
\hline Ator externo & $\begin{array}{l}\text { Barraqueiros } \\
\text { (donos de castanhais), } \\
\text { madeireiros e } \\
\text { fazendeiros }\end{array}$ & $\begin{array}{l}\text { Grandes fazendeiros } \\
\text { de gado }\end{array}$ & $\begin{array}{l}\text { - Geleiras (Pescadores } \\
\text { comerciais) } \\
\text { - Grandes empresas } \\
\text { madeireiras }\end{array}$ & $\begin{array}{l}\text { Grandes empresas } \\
\text { madeireiras }\end{array}$ \\
\hline Desafios & $\begin{array}{l}\text { Expansão do controle } \\
\text { externo sobre } \\
\text { terras usadas pelas } \\
\text { comunidades para } \\
\text { coletar castanha }\end{array}$ & $\begin{array}{l}\text { Fazendeiros } \\
\text { expulsando } \\
\text { seringueiros de } \\
\text { suas colocações para } \\
\text { plantar pasto }\end{array}$ & $\begin{array}{l}\text { - Sobrepesca e } \\
\text { redução de oferta } \\
\text { local de pescado } \\
\text { - Exploração } \\
\text { predatória de madeira }\end{array}$ & $\begin{array}{l}\text { Exploração predatória } \\
\text { de madeira do } \\
\text { fundo das áreas } \\
\text { comunitárias sem } \\
\text { recompensa }\end{array}$ \\
\hline $\begin{array}{l}\text { Interesse da } \\
\text { comunidade }\end{array}$ & $\begin{array}{l}\text { Manter castanhais } \\
\text { sob controle local }\end{array}$ & $\begin{array}{l}\text { Evitar a perda das } \\
\text { áreas de coleta de } \\
\text { seringa e castanha }\end{array}$ & $\begin{array}{l}\text { Controlar pesca e } \\
\text { extração predatória } \\
\text { de madeira }\end{array}$ & $\begin{array}{l}\text { Forçar os madeireiros } \\
\text { a negociar e pagar } \\
\text { pela Madeira } \\
\text { explorada }\end{array}$ \\
\hline
\end{tabular}


estabelecidos, e o Sindicado apoiou as comunidades na busca pelo reconhecimento formal pelo governo. Em 1996, como consequência das ameaças de grandes empresas madeireiras, o Comitê de Desenvolvimento Sustentável de Porto de Moz foi criado como uma rede de organizações do movimento social local. Por intermédio do Comitê, as comunidades organizaram a demarcação de áreas comunitárias e fortaleceram a demanda pelo reconhecimento de seus direitos fundiários.

Em Masisea, as comunidades indígenas Shipibo-Conibo criaram uma organização em 1980 para representar sua luta para o reconhecimento de seus territórios ancestrais. Nove anos mais tarde, a organização, que inicialmente teve um caráter regional, foi descentralizada em diferentes representações provinciais, incluindo a organização de Masisea, denominada Ordim, que conseguiu pressionar agências de governo para a criação dos territórios indígenas.

Todas as organizações mencionadas tinham a missão de representar os interesses de seus membros. As decisōes são tomadas em assembleias e eleições (Tabela 2). Em todos os casos, as organizaçōes ofereceram às comunidades um fórum para discussão e decisão sobre as ações a realizar. Elas também serviram como meio para mobilizar e organizar maior número de comunidades, oferecendo escala e coordenação. Por fim, as organizaçōes conduziram importantes protestos pelos quais as comunidades poderiam expressar seus interesses politicamente.
A conclusão de que as relações conflituosas com atores externos tiveram um papel decisivo na mobilização das comunidades também pode ser observada no fato de que as famílias e comunidades com relaçóes paternalistas com atores externos não se envolveram no movimento local. Um membro de comunidade em Vaca Diez assim descreve:

Quando as marchas aconteceram, já havia alguns grandes proprietários de terra ocupando áreas adjuntas à área comunitária. Eles ofereciam trabalhos para algumas famílias e a relação de vizinhança era boa. Quando a marcha aconteceu, nós incluímos esses proprietários como membros de nossa comunidade, evitando que eles perdessem suas terras na reforma agrária.

\section{Reconhecimento dos sistemas de governança local}

Em todas as regiōes analisadas, as exigências feitas pelas comunidades locais e suas organizações representativas receberam pouca atenção na arena política. Apenas por meio de alianças com parceiros externos poderosos, as exigências foram reconhecidas. Essas alianças forneceram o apoio necessário para as organizaçóes representativas acessarem as agências governamentais e, em alguns casos, até mesmo para chamar a atenção de sociedades nacionais e internacionais (Tabela 3).

Tabela 2

Organizações e seus Mecanismos para Representação

\begin{tabular}{lllll}
\cline { 2 - 4 } & $\begin{array}{l}\text { Federação de } \\
\text { Camponeses } \\
\text { da Província de Vaca } \\
\text { Diez }\end{array}$ & $\begin{array}{l}\text { Sindicato dos } \\
\text { Trabalhadores } \\
\text { Rurais de Xapuri }\end{array}$ & $\begin{array}{l}\text { Comitê de } \\
\text { Desenvolvimento } \\
\text { Sustentável de Porto } \\
\text { de Moz }\end{array}$ & $\begin{array}{l}\text { Organizaçáo } \\
\text { Distrital de Masisea } \\
\text { (Ordim) }\end{array}$ \\
\hline Início & 1953 & 1977 & 1996 & 1989 \\
\hline $\begin{array}{l}\text { Missão conforme } \\
\text { estatuto }\end{array}$ & $\begin{array}{l}\text { Defender seus } \\
\text { membros e suas áreas }\end{array}$ & $\begin{array}{l}\text { Defender os direitos } \\
\text { dos trabalhadores } \\
\text { rurais }\end{array}$ & $\begin{array}{l}\text { Apoiar a população } \\
\text { local no acesso e } \\
\text { uso sustentável dos } \\
\text { recursos naturais }\end{array}$ & $\begin{array}{l}\text { Defender os direitos } \\
\text { indígenas ao território, } \\
\text { identidade, educação e } \\
\text { acesso aos recursos }\end{array}$ \\
\hline Assembleias & Duas vezes por mês & Duas vezes por ano & Quatro vezes por ano & Três vezes por ano \\
\hline Eleiçóes & A cada dois anos & A cada dois anos & A cada três anos & A cada três anos \\
\hline
\end{tabular}


As comunidades em Vaca Diez primeiro aliaram-se a uma ONG local e conseguiram argumentar que sua economia extrativista tradicional era dependente da manutenção de extensas terras comunitárias para a coleta de castanha no Brasil. A ONG, além de seus canais de divulgação, ofereceu prova técnica e científica de que cada família precisava de pelo menos 500 ha (450 ha para a extração de castanha e 50 ha para a agricultura). Mais tarde, a ONG também ofereceu treinamento em questões legais, fornecendo advogados profissionais para representar as comunidades em debates políticos. Além disso, a igreja deu apoio financeiro à Comissão de Reforma Agrária (Comisión de Saneamiento del Norte), criada para demarcar áreas de comunidades sob a lei reformulada. Esta aliança também permitiu que as comunidades posicionassem suas demandas no âmbito nacional de reforma institucional, o que resultou na Lei de Participação Popular.

Xapuri é um exemplo bem conhecido de comunidades que, por meio de alianças estratégicas com parceiros influentes, levaram o governo a adaptar os modelos de posse da terra às suas demandas. $\mathrm{O}$ apoio inicial foi dado pela igreja católica e pelo Partido dos Trabalhadores (PT), por intermédio do qual alguns representantes da comunidade até mesmo se tornaram parlamentares e prefeitos. No entanto, somente a partir de alianças estratégicas com ONGs ambientalistas é que as comunidades conseguiram força para ter seus direitos de posse à terra reconhecidos. Remodelaram também a partir daí sua reividicação inicial para manter suas colocaçôes, resultando na formação de reservas extrativistas e na elaboração de projetos de assentamento agroextrativistas, novos conceitos no âmbito de gestão ambiental.

Em Porto de Moz, a igreja católica de forma semelhante ajudou as famílias ribeirinhas a se organizarem. No entanto, desde os anos de 1980, as comunidades tentaram, sem sucesso, ter seus acordos de pesca e áreas comunitárias reconhecidos pelos órgãos governamentais responsáveis. Finalmente, no início de 2000, uma aliança com uma ONG ambiental internacional ofereceu apoio para as comunidades que adaptaram suas demandas para o modelo existente de Reserva Extrativista. A ONG prestou serviços de consultoria para questôes conceituais e legais e apoiou o movimento local na organização de uma campanha pública marcada pelo fechamento do rio Jaurucu, para impedir a passagem de balsas transportando madeira. Juntos,

Tabela 3

Implicações das Conquistas Resultantes das Alianças com Atores Externos

\begin{tabular}{|c|c|c|c|c|}
\hline & Vaca Diez & Xapuri & Porto de Moz & Masisea \\
\hline Parceiros & ONG Nacional & $\begin{array}{l}\text { ONG ambientalista } \\
\text { internacional }\end{array}$ & $\begin{array}{l}\text { ONG ambientalista } \\
\text { internacional }\end{array}$ & ONG ambientalista \\
\hline $\begin{array}{l}\text { Demanda por } \\
\text { reconhecimento }\end{array}$ & $\begin{array}{l}\text { Áreas comunitárias } \\
\text { tradicionais para } \\
\text { coleta de castanha }\end{array}$ & $\begin{array}{l}\text { Manutenção das } \\
\text { colocaçóes para coleta } \\
\text { de castanha e borracha }\end{array}$ & $\begin{array}{l}\text { Acordos de pesca e } \\
\text { áreas comunitárias }\end{array}$ & Territórios tradicionais \\
\hline Conquistas & $\begin{array}{l}500 \text { ha por família } \\
\text { vivendo em } \\
\text { comunidade }\end{array}$ & $\begin{array}{l}\text { Reservas extrativistas } \\
\text { e assentamentos agro- } \\
\text { extrativistas }\end{array}$ & Reserva extrativista & Territórios indígenas \\
\hline $\begin{array}{l}\text { Implicações das } \\
\text { conquistas }\end{array}$ & $\begin{array}{l}\text { - Apenas as } \\
\text { famílias vivendo } \\
\text { em comunidades } \\
\text { receberam terra. } \\
\text { - Necessidade de } \\
\text { planos de manejo para } \\
\text { coletar castanha. }\end{array}$ & \multicolumn{2}{|c|}{$\begin{array}{l}\text { - A terra permaneceu pública e as famílias } \\
\text { receberam apenas o direito de uso. } \\
\text { - Planos de manejo passaram a ser necessários } \\
\text { e as unidades de conservação implicam em } \\
\text { diferentes restriçōes para o uso da terra. }\end{array}$} & $\begin{array}{l}\text { Muitas comunidades } \\
\text { receberam } \\
\text { significantemente } \\
\text { menos terra do que } \\
\text { esperado }\end{array}$ \\
\hline
\end{tabular}


começaram a fazer lobby para tornar a área uma reserva extrativista, evitando assim a extração ilegal de madeira e, ao mesmo tempo, garantindo direitos consuetudinários à terra e a recursos naturais. Como resultado, a Reserva Extrativista Verde para Sempre foi criada em novembro de 2004.

Em Masisea, as organizações indígenas foram apoiadas pelo Sistema Nacional de Mobilização Social (Sinamos), uma agência governamental criada para promover a organização de famílias ribeirinhas indígenas. Mais tarde, a organização coordenou o movimento para o reconhecimento legal dos territórios indígenas. Sua estratégia principal foi a negociação de longo prazo com o governo nacional. Uma vez que os territórios foram reconhecidos, o movimento recebeu apoio financeiro considerável de alguns países europeus.

A pesquisa também avaliou as adaptações feitas pelas comunidades em suas demandas originais, em função das parcerias estabelecidas para fortalecer suas reivindicaçôes. Uma observação comum foi de que, apesar das conquistas importantes, essas alianças geralmente forçaram as comunidades a se adaptar aos interesses e argumentos de seus parceiros mais poderosos. No curso da negociação, as demandas iniciais foram frequentemente adaptadas aos interesses dos novos aliados. $\mathrm{Na}$ maioria dos casos, isso provocou consequências inesperadas para as comunidades.

Em Vaca Diez, as conquistas alcançadas excluíram as famílias que viviam fora das comunidades, e as comunidades que se beneficiaram da reforma agrária tiveram que começar a preparar planos formais de manejo para a gestão de coleta de castanha, o que aumentou significativamente a burocracia. Em Xapuri, as famílias adaptaram suas demandas para manter suas colocações ao modelo de Reserva Extrativista sugerido pelas ONGs ambientalistas. As famílias por conta disso não se tornaram proprietárias de suas áreas, mas apenas adquiriram o direito de uso dos recursos com base em planos de gestão aprovados pelo órgão governamental responsável.

Em Porto de Moz, o conceito local embrionário de áreas comunitárias foi substituído pelo modelo de Reserva Extrativista conforme orientação da $\mathrm{ONG}$ parceira. Em adição às restriçôes aplicadas em Xapuri, as famílias sofreram com a indefinição sobre a possibilidade de criação de búfalos na reserva, uma atividade tradicional antes da criação da unidade, mas proibida pela legislação em unidades de conservação. Além disso, as decisôes importantes agora são feitas por atores externos, tais como agências governamentais, e influenciadas por organizações não governamentais. Mesmo as organizações comunitárias representativas perderam a maior parte de sua influência na tomada de decisões sobre assuntos locais, que passaram a ser feitas de maneira colegiada. Em Masisea, as demandas das famílias por território foram reconhecidas, mas, em alguns casos, com áreas inferiores ao que tinha sido proposto. Atualmente as comunidades precisam lutar pela ampliação de seus territórios.

Um membro de organização representativa, entrevistado em Porto de Moz, declarou:

Aqui temos essas iniciativas locais (acordos de pesca e áreas comunitárias) que estão agora se envolvendo em um contexto mais amplo. Estamos agora em um momento em que as decisões passam a ser feitas de fora das comunidades, influenciadas por ONGs e governos. Como existem tantos interesses envolvidos, corremos o risco de que esse processo não evolua. Se não continuarmos construindo alianças com parceiros-chave, não temos voz nesse debate.

\section{Discussão}

As comunidades estudadas na fronteira amazônica desenvolveram sistemas de governança na tentativa de restringir o acesso por agentes externos aos recursos localmente valiosos. Em casos de relaçôes impessoais (não paternalistas) e conflituosas com atores externos, as comunidades organizaram-se para implementar seus sistemas de governança. Quando formaram alianças com parceiros poderosos, como organizações ambientalistas, elas conseguiram o suporte necessário para reivindicar o reconhecimento desses sistemas de governança (Tabela 4). 
Tabela 4

Circunstâncias (Causas) Favorecendo as Comunidades a

Desenvolver Sistemas de Governança (Consequências)

\begin{tabular}{lll} 
& Circunstâncias (Causas) & Consequências \\
\hline Desenvolvimento & $\begin{array}{l}\text { Chegada de atores externos acessando recursos } \\
\text { das comunidades sem negociação prévia }\end{array}$ & $\begin{array}{l}\text { Comunidades tentam regular o acesso por } \\
\text { atores externos a recursos com importância } \\
\text { local, em alguns casos desenvolvendo sistemas } \\
\text { de governança }\end{array}$ \\
\hline Organização & $\begin{array}{l}\text { Relações impessoais e conflituosas com atores } \\
\text { externos }\end{array}$ & $\begin{array}{l}\text { Comunidades identificam interesses comuns e } \\
\text { organizam-se para implementar e defender seus } \\
\text { sistemas }\end{array}$ \\
& & $\begin{array}{l}\text { Comunidades recebem apoio para barganhar } \\
\text { pelo reconhecimento de seus sistemas de } \\
\text { governança }\end{array}$ \\
\hline
\end{tabular}

\section{Desenvolvimento de sistemas de governança}

Estudos anteriores demonstraram os atributos dos recursos de uso comum e de seus usuários que podem incentivar a auto-organização (Ostrom, 1999; Conroy et al., 2002). No entanto, esta pesquisa monstrou que, na fronteira amazônica, sistemas de governança foram adotados por parte das comunidades para regular o acesso a recursos locais por agentes externos. A implementação desse sistema foi suscitada pela chegada de atores externos que acessavam os recursos da comunidade sem negociações prévias. Assim, tais sistemas podem ser mais bem interpretados como uma resposta defensiva às ameaças externas do que como uma formulação de conceitos baseada nos atributos de recursos e usuários.

Comunidades e agentes externos disputaram particularmente os recursos naturais, como castanha, borracha, madeira e peixe. Na Amazônia, portanto, a luta pela posse da terra, que é, supostamente, a causa da maior parte dos movimentos sociais da América do Sul (Martins, 1981; Ianni, 1985), é uma estratégia para garantir acesso aos recursos naturais. $\mathrm{O}$ foco da luta não é a terra em si, mas os recursos naturais nela existentes. Em outras áreas de fronteira da Amazônia, os movimentos comunitários também almejavam o acesso aos recursos naturais (Pinedo-Vasquez et al., 1992; Crespo e Fernández, 2001).

\section{Organização das comunidades}

Estudos sobre ação coletiva segerem que as comunidades enfrentam vários desafios para se organizar (ver, por exemplo, Scott, 1985; Futemma et al., 2002; Thorp et al., 2005; Abers, 2007). Particularmente na fronteira amazônica, relaçōes paternalistas com agentes externos criam dependência e impedem a organização local (Medina e Shanley, 2004). No entanto, este estudo mostrou que relaçôes impessoais (em contraste com paternalistas) e conflituosas com agentes externos favorecem o surgimento de organizações comunitárias. Embora algumas investigaçōes tenham enfatizado as consequências destrutivas de conflitos e buscado formas de mediação (Yasmi, 2007), estudos sobre movimentos sociais demonstram que o conflito é um mecanismo de mobilização importante para os grupos (Della Porta e Diani, 2006). De acordo com Crespo e Fernández (2001), os conflitos tornam explícitas as desigualdades e servem como meio para superar as diferenças. Garcia-Linera (2004) destacou que os movimentos sociais muitas vezes são formados em oposição (real ou fictícia) a outras entidades e que um elemento central neste processo é a identificação de inimigos comuns.

Este estudo também mostrou a importância de organizaçōes representativas para expressar os interesses politicos das comunidades locais. Dada a sua estrutura democrática, com assembleias e eleiçōes, 
essas organizações são frequentemente mais bem equipadas do que as ONGs de desenvolvimento para proporcionar uma representação política legítima às comunidades da Amazônia. Harvey (2003) sugeriu que as melhores formas de ação para representar os mais pobres devem surgir da sua experiência particular de sujeição. Em alguns casos, essas organizações apontam para mudanças estruturais na sociedade. Assim, elas podem ser entendidas como representantes de uma classe social no sentido marxista, ou seja, um grupo organizado em torno de objetivos comuns e contra outra classe.

\section{Reconhecimento dos sistemas de governança}

Mesmo quando a ação coletiva emerge, as organizações de comunidades representativas enfrentam desafios relacionados com o quadro político (Albaladejo e Veiga, 2002; Muñoz et al., 2007). Muñoz et al. revelaram que a ação coletiva bem-sucedida requer agentes com os quais as comunidades possam interagir. Geralmente, esses agentes não são acessíveis às comunidades em países sul-americanos, que têm feito muito pouco para criar espaços de participação, seja na sociedade seja no Estado (Martins, 1999).

Nesse contexto, as alianças com poderosos parceiros externos, tais como organizações ambientalistas, foram uma ferramenta importante usada pelas comunidades locais para expressar suas demandas. Albro (2005) mostrou que os movimentos sociais podem relacionar questôes locais com questões externas por meio de analogias políticas com grande poder de convencimento. Considerando as dificuldades em controlar o desmatamento na fronteira da Amazônia, as organizações ambientalistas têm encontrado nas comunidades locais aliados naturais.

Em alianças com parceiros externos, as comunidades acabaram se adaptando aos interesses e conceitos de seus parceiros. Esse fenômeno tem sido explorado por Schmink e Wood (1992), que indicaram que os grupos indígenas e seringueiros, na tentativa de se protegerem de fazendeiros invasores, exaltaram a sabedoria da cultura tradicional e suas virtudes da conservação da floresta. Ao fazer isso, eles estabeleceram afinidade com o movimen- to ambientalista internacional, que desde então os apoia. De acordo com Ianni (1985), nesse processo, o campesinato sempre corre o risco de tutela por parte de atores externos. De acordo com Martins, “a história política do campesinato não pode ser entendida separadamente da história das lutas dos atores externos pela sua tutela política" (1981, p. 81). O papel dos parceiros externos das comunidades rurais na Amazônia é, obviamente, altamente ambivalente.

Comunidades na fronteira amazônica e suas organizações representativas estão gerindo um dilema crucial: eles podem insistir na sua autonomia como pré-requisito para o desenvolvimento local de acordo com seus interesses e capacidades, mas correm o risco de ser ignorados. Ou podem colocar seu destino nas mãos de estranhos poderosos, assumindo compromissos com agentes externos (incluindo governos e ONGs) em troca de ter ao menos alguns de seus intereses reconhecidos.

\section{Conclusão}

Os estudos de caso revelaram que as relações autônomas (não dependentes) com agentes externos foram fundamentais para permitir que as comunidades desenvolvessem seus próprios sistemas no intuito de regular o acesso e o uso de recursos naturais de acordo com a perspectiva do local. Quando as comunidades são dependentes de agentes externos, elas têm possibilidades limitadas para gerenciar seus recursos e se organizar em torno de objetivos comuns (Medina et al., 2009b). Conforme argumentado por Ray e Bijarnia (2007), uma condição primária para o desenvolvimento local é a remoção da dependência dos subordinados em relação aos poderosos. Para as comunidades na fronteira amazônica, o desenvolvimento local, portanto, depende principalmente de suas oportunidades para estabelecer relações autônomas com atores que chegam, seja o Estado seja o setor empresarial. As comunidades não dependentes são capazes de liderar seu próprio desenvolvimento, fortalecer os papéis da sociedade como um todo, e em especial das populaçôes locais. 
Esse estudo mostrou que, na fronteira amazônica, as próprias comunidades procuraram se tornar menos dependentes em vez de serem encorajadas a fazê-lo por atores externos. Isto não nega a contribuição destes à promoção do desenvolvimento local, mas indica que a relação deve ser construída a partir do equilíbrio de poder entre comunidades locais e agentes externos. Isso é fundamental para que as comunidades realmente participem como protagonistas autônomas do desenvolvimento local.

\section{BIBLIOGRAFIA}

ABERS, R. (2007), "Organizing for governance: building collaboration in Brazilian river basins". World Development, 35 (8): 1450-1463.

ALBALADEJO, C. \& VEIGA, I. (2002), "Condiçôes e limites da gestão concertada dos recursos naturais a nível local: reflexões sobre um projeto de manejo florestal na Amazônia Oriental”. Agricultura Familiar, 1 (3): 173-208.

ALBRO, R. (2005), "The indigenous in the plural in Bolivian oppositional politics". Bulletin of Latin American Research, 24 (4): 433-453.

ALLEGRETTI, M. (1990). "Extractive reserves: an alternative for reconciling development \& environmental conservation in Amazonia, in A. Anderson (ed.). Alternatives to Deforestation: Steps Toward Sustainable Use of the Amazon Rain Forest. New York, NY, Columbia University Press, pp. 252-264.

ARNOLD, J. (1998), "Managing forests as common property". FAO Forestry Paper 136. Rome, FAO.

BALLABH, V.; BALOONI, K. \& DAVE, S. (2002), "Why local resources management institutions decline: a comparative analysis of Van (Forest) Panchayats \& forest protection committees in India”. World Development, 30 (12): 2153-2167.

BONIFAZ, C. (2005), "El proceso constituyente boliviano: el hito de la cuarta marcha de tierras bajas. Santa Cruz de la Sierra, Cejis.

BROCKNGTON, D. (2007), "Forests, community conservation, and local government performance: the village forest reserves of
Tanzania”. Society \& Natural Resources, 20: 835-848.

CAMPBELL, B.; De JONG, W.; LUCKERT, M.; MANDONDO, A.; MATOSE, F.; NEMARUNDWE, N. \& SITHOLE, B. (2001), "Challenges to proponents of CPR systems: despairing voices from the social forests of Zimbabwe". World Development, 29: 589-600. CLEAVER, F. (2005), "The inequality of social capital \& the reproduction of chronic poverty". World Development, 33 (6): 893-906.

CONROY, C.; MISHRA, A. \& RAI, A. (2002), "Learning from self-initiated community forest management in Orissa, India”. Forest Policy \& Economics, 4 (3): 227-237.

CRESPO, C. \& FERNÁNDEZ, O. (2001), Los campesinos regantes de Cochabamba en la guerra del agua: una experiencia de presión social y negociación. Cochabamba, Bolivia, Universidad Mayor de San Simon, Centro de Estudios Superiores Universitarios.

DE JONG, W. (2004). Retos y perspectivas del nuevo régimen forestal en el norte amazónico boliviano. Bogor, Indonésia, Cifor.

DELLA PPORTA, D. \& DIANI, M. (2006). Social movements: an introduction. Malden, MA, Blackwell.

DOVE, M. (1993), "A revisionist view of tropical deforestation \& development”. Environmental Conservation, 20 (1): 17-55.

FLINT, C.; LULOFF, A. \& FINLEY, J. (2008), "Where is 'community' in community-based forestry?”. Society \& Natural Resources, 21 (6): 526-537.

FUTEMMA, C.; CASTRO, F.; SILVA-FORSENBERG, M. \& OSTROM, E. (2002), "The emergence \& outcomes of collective action: an institutional \& ecosystem approach". Ambiente \& Sociedade, 5 (10): 1-21.

GARCIA-LINERA, A. (2004), Sociología de los movimientos sociales en Bolivia: estructuras de movilización, repertorios culturales y acción politica. La Paz, Diakonia \& Oxfam.

HARVEY, D. (2003), The new imperialism. Oxford, Oxford University Press.

HICKEY, S. \& Bracking, S. (2005), "Exploring the politics of chronic poverty: from represen- 
tation to a politics of justice?". World Development, 33 (6): 851-865.

IANNI, O. (1985), "Revoluções camponesas na América Latina", in J. T. dos Santos, Revoluçôes camponesas na América Latina, São Paulo, Editora da Unicamp/Ícone.

LEROY, J. (1991), Uma chama na Amazônia. Petrópolis/Rio de Janeiro, Vozes/Fase.

LURIE, S. \& HIBBARD, M. (2008), "Community-based natural resource management: ideals $\&$ realities for Oregon Watershed Councils". Society \& Natural Resources, 21 (5): 430-440.

MARTINS, J. (1981), Os camponeses e a politica no Brasil. Petrópolis, Vozes.

- (1997), Fronteira: a degradação do outro nos confins do humano. São Paulo, Hucitec. . (1999), O poder do atraso: ensaios de sociologia da história lenta. São Paulo, Hucitec.

MEDINA, G. \& SHANLEY, P. (2004), "Big trees, small favors: Loggers \& communities in Amazônia”. Bois \& Forêts dês Tropiques, 282 (4): 19-25.

MEDINA, G.; POKORNY, B. \& CAMPBELL, B. (2009a), "Community forest management for timber extraction in the Amazon frontier". International Forestry Review, 11: 408-420.

(2009B), "Loggers, development agents $\&$ the exercise of power in Amazonia". Development \& Change, 40: 745-767.

MOREIRA, E. (2004), Tradição em tempos de modernidade: reprodução social numa comunidade varzeira do rio Xingu-Pa. Belém, EDUFPA.

MUNOOZ, I.; PAREDES, M. \& THORP, R. (2007), "Group inequalities \& the nature \& power of collective action: case studies from Peru”. World Development, 35 (11): 1929-1946.

OSTROM, E. (1999), "Self-governance \& forest resources". Occasional Paper n. 20. Bogor, Cifor.

PÉREZ-CIRERA, V. \& LOVETT, J. (2006), "Power distribution, the external environment $\&$ common property forest governance: a local user groups model”. Ecological Economics, 59: 341-352.

PINEDO-VASQUEZ, M.; ZARIN, D. \& JIPP, P. (1992), "Community forest $\&$ lake reserves in the Peruvian Amazon: a local alternative for sustainable use of tropical forests". Advances in Economic Botany, 9: 79-86.
RAY, S. \& BIJARNIA, M. (2007), "Power relations $\&$ institutional outcomes: a case of pastureland development in semi-arid Rajasthan". Ecological Economics, 62: 360-372.

RICHARDS, M. (1997), "Common property resource institutions \& forest management in Latin America". Development \& Change, 28: 95-117.

SALGADO, I. \& KAIMOWITZ, D. (2003), "Porto de Moz: o prefeito, 'dono do município", in F. Toni e D. Kaimowitz (eds.), Municipios e gestão florestal na Amazônia, Natal, A. S. Editores, pp. 219-252.

SCHMINK, M. \& WOOD, C. (1992), Contested frontiers in Amazonia. Nova York, Columbia University Press.

SCOTT, J. (1985), "Weapons of the weak: everyday forms of peasant resistance". New Haven, Yale University Press.

SYCK, D. (2008), "Social contexts \& consequences of institutional change in common-pool resource management". Society \& Natural Resources, 21 (2): 94-105.

THORP, R.; STEWART, F. \& HEYER, A. (2005), "When $\&$ how far is group formation a route out of chronic poverty?". World Development, 33 (6): 907-920.

YASMI, Y. (2007), Institutionalization of conflict capability in the management of natural resources: theoretical perspectives and empirical experience in Indonesia. Wageningen, Wageningen University. 


\section{GOVERNANCCA LOCAL PARA MANEJO FLORESTAL NA AMAZÔNIA}

\section{Gabriel Medina}

Palavras-chave: Sistemas comunitários de gestão florestal; Fronteira amazônica; Movimentos sociais; Desenvolvimento endógeno.

Comunidades da Amazônia podem se beneficiar do uso de seus recursos florestais ao estabelecer sistemas de gestão comunitária de acordo com seus interesses e capacidades. Para isso, no entanto, as comunidades enfrentam três desafios principais: desenvolver os sistemas, implementá-los e conseguir seu reconhecimento pela sociedade. Esse estudo realizado na Amazônia boliviana, brasileira e peruana revelou que sistemas comunitários de gestão florestal existentes na Amazônia surgiram a partir tentativas das comunidades de restringir o acesso de atores externos a recursos de interesse local. Relaçôes conflituosas com atores externos levaram à mobilização e à organização das comunidades. Alianças com parceiros influentes, como organizações ambientalistas, ofereceram às comunidades condiçôes de barganhar para ter seus sistemas reconhecidos. Os resultados sugerem que relações autônomas (em contraste com paternalistas) com atores externos são fundamentais para o desenvolvimento local.

\section{LOCAL GOVERNANCE FOR FOREST MANAGEMENT IN THE AMAZON}

\section{Gabriel Medina}

Keywords: Community-governed forest management; Amazon frontier; Social movements; Endogenous development.

Amazonian communities can greatly benefit from the forest resources they hold by setting up community-governed management systems that reflect their interests and capacities. However, communities face three challenges: to develop the systems, to enforce them, and to have their systems acknowledged by the wider society. This study, carried out in the Bolivian, Brazilian, and Peruvian Amazon, revealed that community-governed systems emerge in an attempt to restrict access by external actors to locally valuable resources. Detached and conflicting relationships with external actors are a crucial factor driving communities to get organized. Alliances with powerful partners, such as environmental organizations, support communities to get their systems acknowledged. These findings suggest that autonomous (in contrast to dependent) relationships with external actors are fundamental for local development.

\section{GOUVERNANCE LOCALE POUR LA GESTION DES FORÊTS EN AMAZONIE}

Gabriel Medina

Mots-clés: Systèmes communautaires de gestion des forêts; Frontière amazonienne; Mouvements sociaux; Développement endogène.

Des communautés en Amazonie peuvent se bénéficier de l'usage de leurs ressources forestières en établissant des systèmes de gestion communautaire suivant leurs intérêts et leurs capacités. Pour cela, les communautés affrontent, néanmoins, trois défis principaux : développer les systèmes, les faire fonctionner et obtenir leur reconnaissance par la société. Cette étude réalisée en Amazonie bolivienne, brésilienne et péruvienne a révélé que les systèmes communautaires de gestion des forêts existants en Amazonie ont surgi à partir de tentatives des communautés de restreindre l'accès d'acteurs externes à des ressources d'intérêt local. Des rapports conflictuels avec des acteurs externes ont mené à la mobilisation et à l'organisation des communautés. Des alliances avec des partenaires influents, comme les organisations environnementales, offrent aux communautés des conditions de négocier pour avoir leurs systèmes reconnus. Les résultats suggèrent que les rapports autonomes (par rapport aux paternalistes) avec des acteurs externes sont fondamentaux pour le développement local. 